\title{
Green economic growth from a developmental perspective
}

\author{
Bei Jin and Gang Li
}

\author{
* Correspondence: Iggui@sina.com \\ Institute of Industrial Economics, \\ Chinese Academy of Social \\ Sciences, No.2, Yuetan Beixiaojie, \\ 100836 Beijing, China
}

\begin{abstract}
This paper discusses the relationship between industrial development and environmental protection. The paper argues that human beings cannot solve the problems linked to the environment and the natural resources in a stagnant manner, nor can human beings achieve sustainable development in the extensive economic growth model of ignoring resource constraints and the environment. The difficulties of China's environmental protection lie in the balance of the relationship between the reform of regulation governing resources and the environmental and the international competitiveness of China's industrial sector, in particular, the balance of the relationship between environmental protection and economic growth. China's industrialization practices show that the country's industrial sector itself has the potential to help promote the improvement of the utilization efficiency of resources and the environment. At the same time, however, it can consume significant resources, causing certain environmental degradation. Industrial processes can have negative environmental impacts, but industrial development can play a positive role in environmental protection and improvement from a global and long-term perspective. It is impossible for China to solve the problems linked to resources and the environment without the development of industrial entities. On the contrary, the pressure on the resources and the environment can only be relieved with more advanced and powerful industries. In China, public opinion on environmental protection has been formed and will become stronger. Therefore, we have reason to be optimistic for the country's environmental protection and improvement.
\end{abstract}

Keywords: Environmental protection; Industrial development; Green economy

Today, constraints on economic development brought about by resources and the environment have become increasingly prominent so that the desire to achieve a green economy, that is, a growth pattern of resource conservation and environmental protection, is becoming stronger and more urgent. How can we solve the problems linked to resources and the environment? One of the keys is to solve the relationship between resource conservation and environmental protection and economic growth. Human beings cannot solve the problems linked to the environment and natural resources in a stagnant manner, and neither can human beings achieve sustainable development in the extensive economic growth model that ignores resource and environmental constraints.

(c) $2013 \mathrm{Jin}$ and Li; licensee Springer. This is an Open Access article distributed under the terms of the Creative Commons Attribution License (http://creativecommons.org/licenses/by/2.0), which permits unrestricted use, distribution, and reproduction in any medium, provided the original work is properly cited. 


\section{The difficulties of China's environmental protection lie in simultaneously achieving growth and environmental protection}

Environmental economics originates from the reality of increasingly serious environmental problems. Since the industrial revolution, the large-scale exploitation of the natural environment has improved mankind's quality while causing environmental deterioration and other problems. Especially, after the end of World War II, the widespread expansion of industrialization and urbanization around the world has been greatly accelerating the consumption of natural resources, resulting in increasingly serious problems of environmental pollution. Some theoretical studies (Porter 1991; Porter and van der Linde 1995) and empirical studies (Jaffe and Palmer 1997; Newell et al. 1999; Berman and Bui 2001; Snyder et al. 2003) show that under certain conditions, environmental regulation has the potential to help achieve both improvement of environmental performance and enhancement of business competitiveness.

However, such win-win results are difficult for a country to achieve due to the fact that the level of the environmental standards that a country's industrial sector is able to withstand are limited by the level of technological advancement and the need to achieve economic growth. As a developing country, the most important task for China for some time will still be to develop rapidly under the guidance of the Scientific Outlook on Development. The difficulties of the country's environmental protection lie in balancing the relationship between reform of regulation governing resources and the environment with the international competitiveness of the country's industrial sector, in particular, the balance of the relationship between environmental protection and economic growth.

\section{While China's high growth has come at the cost of resources and the environment, it has also improved the utilization efficiency of resources and the environment}

In the past, more than 30 years since the start of reform and opening, China's industrial sector has made great progress and attracted worldwide attention. But China has also paid a great cost in terms of resource consumption and environmental degradation. So far, China's rapid industrial development has largely depended on extensive growth, resulting in the country paying the inevitable costs of resources and the environment. However, it is worth noting that the environmental efficiency of the country's industrial sector is rising, which greatly weakens the negative impacts of industrial development on the environment.

As an example, the energy efficiency of the country's industrial sector has been increasing since 1986. China's industrial standard coal consumption per 10,000 yuan of GDP in 1986 was 13.72 tons, which had dropped to 4.63 tons of standard coal by 2,000 (expressed in prices in 1986, the same below; see Figure 1). However, in the initial stage in 2001, China's industrial energy efficiency decreased, and this was related to the new round of rapid development of heavy and chemical industries in China. Industrial energy consumption per 10,000 yuan of GDP in 2005 was 4.88 tons of standard coal. At the same time, energy efficiency reached a historic low. Since then, energy efficiency has begun to increase steadily, and energy consumption per 10,000 yuan of GDP in 2010 was only 3.84 tons of standard coal. China's industrialization practices show that the 


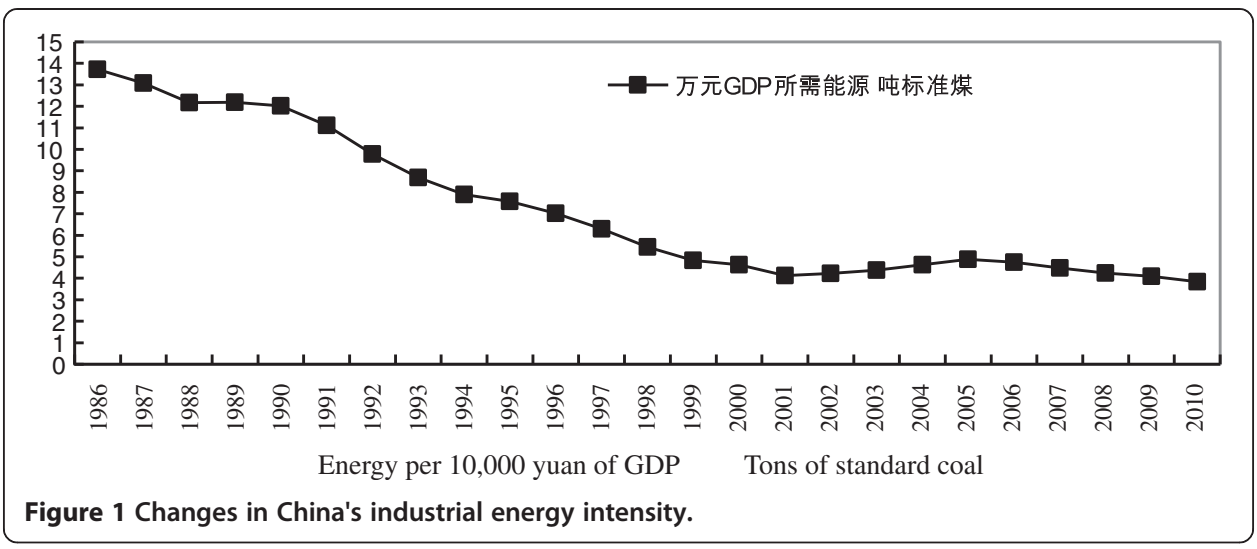

country's industrial sector itself has the potential to help promote the improvement of the utilization efficiency of resources and the environment. At the same time, however, it can consume substantial resources, causing certain environmental degradation. Moreover, the more developed the country's industrial sector, the better the material and technical conditions are for solving the problems linked to the resources and the environment.

\section{Industrialization can lay the material and technical foundation for solving problems linked to resources and the environment}

Indeed, the industrial sector can have negative environmental impacts as viewed from industrial production processes. On one hand, the industrial sector can consume a great deal of non-renewable resources. On the other hand, some harmful substances (i.e., exhaust gas, waste water, waste materials) will be generated in the process of industrial production. As is well known, it is impossible to solve the problems linked to resources and the environment without the development of industrial entities. On the contrary, pressure on resources and the environment can only be relieved by a more developed and powerful industrial sector. Substances on the earth could originally not be classified as 'resources' and 'waste'. Without industrialization, most of the substances would be waste rather than resources. With the support of science and technology and an advanced and developed industrial sector, all substances can be changed into resources, and even wastes can be transformed to benefit human beings. Industrialization has the potential to help create a living environment for human beings. At the same time, industrial processes can have negative environmental impacts. Improper industrial exploitation can cause damage to the environment, but the environment can only be protected and improved by more developed industrial technologies. Therefore, the key is to increase the green level of industrialization, and to solve the problems linked to resources and the environment in China with a more developed and advanced industrial sector.

Researchers of the Institute of Industrial Economics of the Chinese Academy of Social Sciences recently carried out field research in Xixia County, a protected area of industrial water sources in the middle region of the South-to-North Water Transfer Project. The Ministry of Environmental Protection of the People's Republic of China named Xixia County as a Nationally Designated Eco-Demonstration Region in May 2008. As a mountainous county of the central region in a middle stage of industrialization, the county has made great achievements in environmental protection. Will more stringent 
environmental protection in Xixia County affect its economic development, particularly its industrial development? According to the field research, it will not. While Xixia County has made great achievements in environmental protection, its economy (especially the industrial sector) has been growing rapidly. In fact, the Xixia County's achievements in environmental protection are largely due to the conditions created by the rapid development of the county's industrial sector. By contrast, neighboring Xichuan County has basically same natural conditions as those of Xixia County, and its original ecological environment is similar. But today, there is a huge difference between the ecological environments of the two counties. Xixia County presents green mountains and rivers, while Xichuan County presents vast stretches of bald mountains.

One of the reasons that led to such a difference between the ecological environments of the two counties lies in the difference of their industrial development. On one hand, industrial development has the potential to help accumulate wealth for society rapidly so that more financial resources can be allocated for environmental protection under the premise of meeting the needs of basic livelihood. On the other hand, industrialization can also absorb more agricultural population originally living on mountain forest resources and land resources, and this can help reduce nonpoint agricultural pollution.

With the financial resources provided by the industrial development, Xixia County has the ability to invest significant amounts of money in ecological projects, water pollution prevention, immigrant resettlement, adjustment to the industrial structure, and other areas. Governments at the county are able to receive a certain amount of ecological compensation from the central government as transfer payments, but these limited transfer payments alone are insufficient. A large proportion of funds invested by Xixia County for ecological and environmental protection mainly come from the local government tax revenue, which comes from the local industrial sector, especially its large industrial enterprises.

A relatively ample financial capacity can support the development of green and highefficiency agriculture so as to create conditions to reduce agricultural non-point source pollution. Now, the difficulty of preventing environmental pollution in China has shifted from point source pollution to non-point source pollution. The former is caused by the industrial sector, and the latter is caused by agriculture and life. Developing high-efficiency and green agriculture will not only increase farmer incomes but also reduce the use of pesticides and fertilizers, resulting in significant reduction of non-point source pollution caused by agriculture. For example, planting kiwi trees is a typical type of high-efficiency and green agriculture. It takes 3 to 5 years from investment to planting to producing benefits. Without the government's guidance or support, it is difficult for farmers to carry out a long-term investment in such a field. To reduce agricultural nonpoint source pollution, the government of Xixia County has actively guided farmers to develop local organic agriculture with low pollution. In doing so, the government has provided farmers with more infrastructure and technical support services. For example, in order to promote the planting of organic and harmless kiwi trees, the government contributed to the building of a kiwi fruit production base, setting the cement piles and barbed wires for kiwi trees to climb, and spent money on buying kiwi seedlings for farmers to grow. The government of Xixia County has been able to allocate funds to subsidize farmers to plant kiwi trees because the industrial development of the Xixia County provides sufficient financial resources. 
The development of local industry has the potential to absorb a large number of transferred agricultural labors, and also to create the conditions to reduce agricultural nonpoint source pollution. The industrial development of the Xixia County has absorbed a lot of agricultural population originally living on mountain forest resources and land resources. The transferred agricultural population, on one hand, will no longer engage in agricultural production, resulting in a reduction of agricultural nonpoint source pollution and deforestation. On the other hand, farmers will be able to consume cleaner energy due to relatively high income from the industrial sector. By contrast, neighboring Xichuan County has basically the same natural conditions as those of the Xixia County, but a significantly lower forest cover rate. One important reason is that its industrial sector is underdeveloped so that it is difficult for the county's industry to absorb a large number of rural labors and thereby reduce dependency on and damage to mountain forest resources.

In short, although industrial production processes can have negative environmental impacts, industrial development can play a positive role in environmental protection and improvement from a global and long-term perspective.

\section{Increasingly strong public opinion is forming regarding environmental protection in China}

It is true that there is a certain trade-off relationship between environmental protection and industrial development under certain actual technical conditions, that is, in order to develop industry, environmental costs have to be paid. If the environmental quality resulting from investment in environmental protection is regarded as a type of 'product', then there is also a certain trade-off relationship between the industrial product and environmental quality. In particular, for a developing country, excessive environmental quality standards can exceed the country's technical and economic capacity, hindering industrial development. As a result, the society tends to tolerate economic entities' use of environmental resources at low prices or even for free in the period of economic underdevelopment.

With the increase of the level of economic development and the improvement of the material life, the people's demand for the environmental quality is becoming higher and higher. Currently, in terms of the trade-off relationship between material products and environmental quality, it is obvious that the masses, especially people in the developed regions of eastern China, would rather give up a certain amount of economic growth to improve environmental quality than bear a greater cost of environmental pollution in exchange industrial achievements as in the initial stage of reform and opening (Bei 2009).

A prominent representation of the aforementioned transformation is characterized by the fact that several mass incidents have occurred in China in recent years because local residents opposed the construction of heavy chemical projects. Complying with the demands of the people, in the Outline of the Twelfth Five-Year Plan for National Economic and Social Development, the Chinese government stated, 'In the face of increasingly enhanced constraints on the resources and the environment, we must increase the sense of crisis and establish a green, low-carbon development concept,' 'accelerate the construction of a resource-saving and environment-friendly pattern of growth and model of consumption, and enhance the ability of sustainable development, 
and proposed to 'improve the laws and regulations and standard system for environmental protection' and 'increase environmental enforcement efforts.' The 18th National People's Congress in particular proposed to build an ecological civilization. Obviously, public opinion regarding environmental protection has been formed in China and will become stronger. This is a strong foundation for China's environmental protection. Therefore, we have reason to be optimistic for China's environmental protection and improvement.

\section{Promoting green growth is provided with a wide space of international cooperation}

As viewed from the history of industrialization of various countries, the relationship between industrial development and environmental protection can be classified roughly as treatment after damage, simultaneous damage and treatment, as well as no damage. In the case of no damage, it is unnecessary to perform treatment because no damage has been caused to the environment. Of course, this is the most ideal case. However, it is difficult for many industrial production activities, particularly in developing countries, to achieve such an industrial roadmap and technological level. In the second case, when any damage to the environment is caused during industrial production activities, treatment will be performed on the environment in a timely manner in order to avoid or minimize external environmental pollution to the extent possible, or even if any external environmental pollution occurs in the industrial production activities, it can be controlled and treated in time. In this case, the recovery of the damaged environment depends on the investment capacity for environmental protection of the economic entities or the society. The first case, that is, treatment after pollution, stresses treatment and disposal after pollution has been generated. Although it is criticized most, it is the most common phenomenon in both early industrialized countries and later developing countries. At first, in order to pursue industrial growth and receive economic benefits, a variety of industrial production activities are carried out unscrupulously at the cost of the destruction of the environment. This will surely result in serious environmental pollution. Then, more resources have to be invested in and higher prices have to be paid for environmental treatment. It is clear that such a traditional path of development does more harm than good for society as a whole. But why is it such a common phenomenon? The historical reasons, of course, due to a lack of investment capacity and technical conditions in the early stage of industrial development. Moreover, the primary goal at the time was to eliminate poverty and become wealthy. But the more important reasons were the gap in the development concept, lack of vision during the early stages of industrialization, and a lack of immediate pain from the consequences of environmental damage. Environmental protection can be valued only due to being awakened after the serious consequences are felt. Of course, the actual important reasons are a poor sense of social responsibility among economic entities and imperfect environmental protection systems. With the development of the economy and the concept of environmental protection, room for the pattern of extensive development has grown increasingly narrow. Demand for green development constantly enjoys popular support.

We used to believe that developed countries would have generally entered an era of slowing economic growth for environmental protection, that is, the importance of the environment would have been overwhelmingly greater than that of the economic output. 
However, the ongoing financial crisis shows that, in fact, developed economies also view economic growth as the bottom line. If the long-term economic recession leads to financial difficulties, there would be lack of support for developing the green economy. But this does not mean that Europe and the USA and other developed countries can once again ignore the green economy. They play a leading role in the technical reserves for green economic growth so that their financial difficulties cannot fundamentally undermine the base of green economic growth. In particular, Europe's more advanced technologies and experience with green economic growth, especially experiences in the construction of institutions, are the strengths that China and other developing countries need. China and other developing countries have broad markets for the use of technologies and experiences of green economic growth and can become the sites for developing and implementing green technologies. Thus, the cooperation of Europe, the USA, and other developed countries with China can greatly promote green economic growth. This is not only conducive to solving problems linked to resources and the environment in China, but would also help European countries find a way out of their economic mess.

Competing interests

The authors declare that they have no competing interests.

\section{Authors' contributions}

BJ proposed the research framework and drafted the manuscript with GL. Both authors read and approved the final manuscript.

\section{Authors' information}

$\mathrm{BJ}$ is a member of the academic committee and director of the Institute of Industrial Economics of the Chinese Academy of Social Sciences and president of China Business Journal. He is an editor-in-chief of China Industrial Economics, Economic Management and China Economist. He is also the vice president of the China Industrial Economic Association and vice president and chairman of the China Regional Economics Association. He has won more than 20 awards at the national level and ministerial level for outstanding achievements in scientific research. He is an expert, enjoying a special government subsidy. GL is a doctor of economics, associate researcher in the Institute of Industrial Economics of the Chinese Academy of Social Sciences, and editorial director of China Economist.

\section{Disclosure}

The content of this paper was addressed on the China-Italy Green Growth International Forum held on November 27, 2012. Some revisions have been made in this publication.

Received: 12 January 2013 Accepted: 8 November 2013

Published: 20 December 2013

\section{References}

Bei J (2009) A Study of the relationship between resources and environment regulation and industrial competitiveness (资源环境管制与工业竞争力矢系研究). China Ind Econ (中国工业经济) 25(3):5-17

Berman E, Bui LTM (2001) Environmental regulation and productivity: evidence from oil refineries. Rev Econ Stat 83 (3):498-510

Jaffe AB, Palmer K (1997) Environmental Regulation and Innovation: A Panel Data Study. Rev Econ Stat 79(4):610-619 Newell RG, Jaffe AB, Stavins RN (1999) The induced innovation hypothesis and energy-saving technological change. Q J Econ 114(3):941-975

Porter ME (1991) America's Green Strategy. Sci Am 264(4):168

Porter ME, van der Linde C (1995) Toward a New Conception of the Environment-Competitiveness Relationship. J Econ Perspect 9(4):97-118

Snyder LD, Miller NH, Stavins RN (2003) The effects of environmental regulation on technology diffusion: the case of chlorine manufacturing. Am Econ Rev 93(2):431-435

doi:10.1186/2196-5633-1-4

Cite this article as: Jin and Li: Green economic growth from a developmental perspective. China Finance and Economic Review 2013 1:4. 